This item was submitted to Loughborough's Research Repository by the author.

Items in Figshare are protected by copyright, with all rights reserved, unless otherwise indicated.

\title{
Estimating cost at the conceptual design stage to optimize design in terms of performance and cost
}

PLEASE CITE THE PUBLISHED VERSION

PUBLISHER

(c) Springer-Verlag

VERSION

AM (Accepted Manuscript)

LICENCE

CC BY-NC-ND 4.0

\section{REPOSITORY RECORD}

Saravi, Mohammad E., Linda B. Newnes, Antony R. Mileham, and Yee M. Goh. 2019. "Estimating Cost at the Conceptual Design Stage to Optimize Design in Terms of Performance and Cost". figshare.

https://hdl.handle.net/2134/10730. 
This item was submitted to Loughborough's Institutional Repository (https://dspace.lboro.ac.uk/) by the author and is made available under the following Creative Commons Licence conditions.

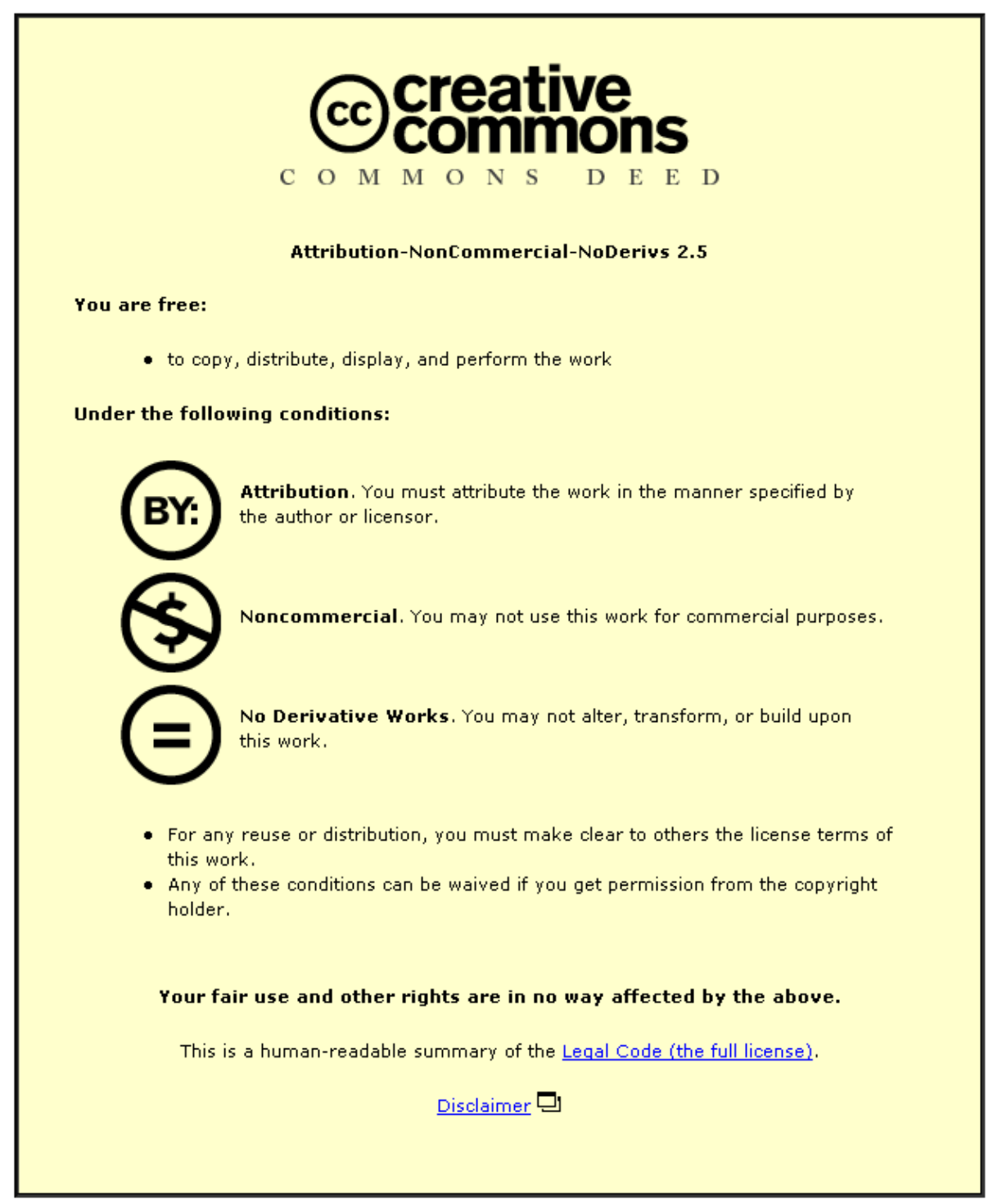

For the full text of this licence, please go to: http://creativecommons.org/licenses/by-nc-nd/2.5/ 


\title{
Estimating cost at the conceptual design stage to optimize design in terms of performance and cost
}

\author{
Mohammad Saravi ${ }^{\mathrm{a}, 1}$, Linda Newnes ${ }^{\mathrm{b}}$ Antony Roy Mileham ${ }^{\mathrm{b}}$ and Yee Mey Goh ${ }^{\mathrm{b}}$ \\ ${ }^{a}$ Mohammad Saravi, University of Bath, Bath, UK. \\ ${ }^{\mathrm{b}}$ Linda Newnes, Antony Roy Mileham and Yee Mey Goh, University of Bath, UK.
}

\begin{abstract}
In the highly competitive business environment, cost estimation is a strategic tool, which can be used to assist decision making with regard to products throughout their life cycle. 70 to 80 percent of the life-cycle costs of a product are determined by decision taken by designers during the early design stages. Therefore it is important to estimate and optimise cost as early and as accurately as possible. The main aim of this research is to use typically available information at the conceptual stage of design and estimate cost in order to optimise design in terms of performance and cost. The main objective is to employ Design of Experiments (Taguchi method) to use the sparse information more effectively in order to estimate the cost of a product at the early design stage. This paper presents the current status of the research activity. A case study is introduced which illustrates the initial applications of the optimization process. Conclusions are then discussed and the future research described.
\end{abstract}

Keywords. Cost estimation, quality techniques (Taguchi method) and conceptual design

\section{Introduction}

One of the difficult tasks undertaken by designers is to evaluate the cost of a new design. When designers start to design a new product, cost is a critical factor in determining whether the product will be viable or not. Nowadays a company needs to estimate the cost of the product and the confidence of that estimate in order to start to design and manufacture a product in detail. Reliable cost estimation of future products plays a significant part for designers in avoiding investing much time and losing considerable sums on non-economically viable products.

Good cost estimation plays a significant part in the performance and effectiveness of a business enterprise as overestimation can result in loss of

${ }^{1} \mathrm{PhD}$ Student, Mechanical Engineering Department, University of Bath, Bath, BA2 7AY, UK; Tel: +44 (0) 1225 386131; Email: mes25@bath.ac.uk; http://www.bath.ac.uk 
business and goodwill, whereas underestimation may lead to financial loss to the enterprise. Asiedu and $\mathrm{Eu}[1]$ state that

- The greater the underestimate, the greater the actual expenditure.

- The greater the overestimate the greater the actual expenditure.

- The most realistic estimate results in the most economical project cost.

70 to $80 \%$ of the product cost is said to be committed by the end of the conceptual design stage [2]. Therefore, it is important to estimate and optimise costs as early as possible since any changes during production are usually very costly. Because of the importance of the conceptual design, cost estimation, at this stage, should be precise and available as soon as possible and provide valuable information to product designers. Despite this importance, having accurate cost estimates at this stage is very difficult. The available data are limited and the designer must depend on the use of various synthetic and parametric techniques in the development of the cost estimates. At this stage, the concept of the product is determined including; overall shape, the main features and materials used, however this limited data makes the estimating process extremely difficult.

The main aim of this research is to use quality technique such as the Taguchi method of Design of Experiments to estimating the cost using the sparse and available information more effectively. In this paper a review of cost estimation techniques, their application in different design stages and available information at the conceptual stage of design is presented and illustrated via a case study.

\section{Importance of Cost Estimation at the Conceptual Design Stage}

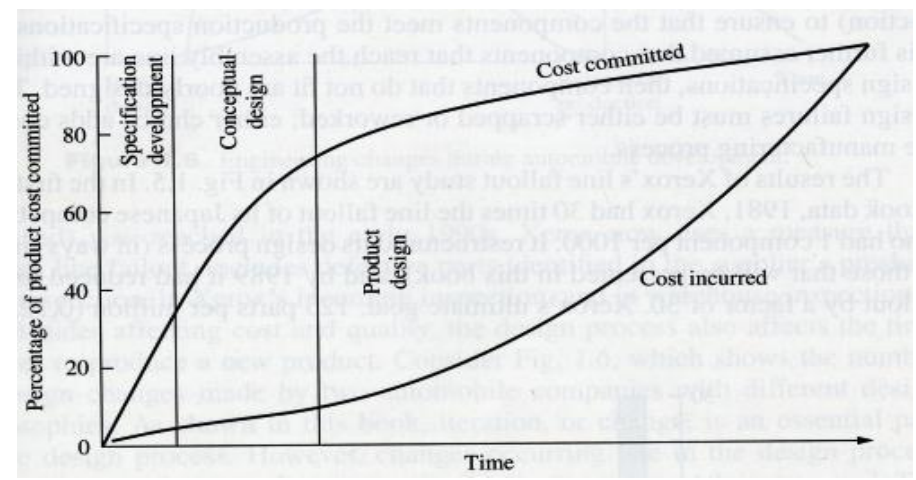

Figure 1. Manufacturing cost commitment during design. [12]

For efficiently achieving the goal of project cost control, accurately estimating the total cost of a system in the early design stage is necessary. Reducing the cost of a product at the early design stage is more effective than at the manufacturing stage. If reliable cost estimates occur during the early design stage, it can help designers to modify a design in order to achieve both performance and cost. Many authors [2, 3 , and 12] have pointed out the importance of cost estimation at the design stage. Corbett [2] indicates that $80 \%$ of a product cost is committed during the early design stage. Mileham [4] states $70-80 \%$ of a product cost is determined during the 
early design stage. Figure 2 shows the importance of cost estimation at the design stage and the cost commitment curve. All these concur that early estimates are important.

\section{Cost Estimation Techniques}

There are several; different methods for evaluating future cost, but not all of these are suitable for the whole lifecycle. Some methods are better than others depending on the context. Farineau [5] explains that cost estimation methods can be divided into four categories; intuitive, analogical, parametric and analytical. Roy [6] describes the cost estimation domain using five methods: traditional, parametric, feature based, case based reasoning and neural networks. Finally, Niazi and Dai [7] categorise cost estimation into qualitative and quantitative approaches. There are three key techniques which have been used by different researchers to estimate costs at the conceptual stage of design including parametric, neural networks and feature-based costing methods.

Parametric models are widely used, and are often used as the primary or, in some cases, the sole basis for estimating. They are especially useful at the early stages of design in a program where detailed information is not yet available [8]. Cmarago and Rabenasolo [8] define a parametric model as a series of Cost Estimation Relationships (CER), ground rules, assumptions, using relationships, variables and constants to describe and define a specific situation. A CER is a mathematical expression, where cost is a function of the cost driver(s) variables.

Neural networks (NN) or artificial neural network (ANN) network simple processing elements to exhibit complex global behavior by connecting the processing elements and element parameters. NN are particularly effective for complex estimating problems where the relationship between variables can not be expressed by simple mathematical expressions [9]. Ayed [9] explains that an ANN can simulate the action of a human expert in a complicated decision situation.

The growth of CAD and CAM technology has played a significant part in the development of feature-based costing. The feature-based cost estimation methodology deals with the identification of a product's cost-related features and the determination of the associated costs [7]. Roy [6] explains that products can be described as a number of associated features such as holes, edges, folds etc.

\section{Conceptual Design \& Available Information at this stage}

For this research the focus is on estimating at the conceptual design stage. Design can be broken into the three major stages including; conceptual design, embodiment design and detailed design [13]. Conceptual design is considered to be the most important stage in design. It is in conceptual design that the basic questions of configuration arrangement size, weight and performance are answered [10]. In the embodiment and detail design stage, material specifications, dimensions, surface condition and tolerances are specified in the fullest possible detail for manufacturing. 


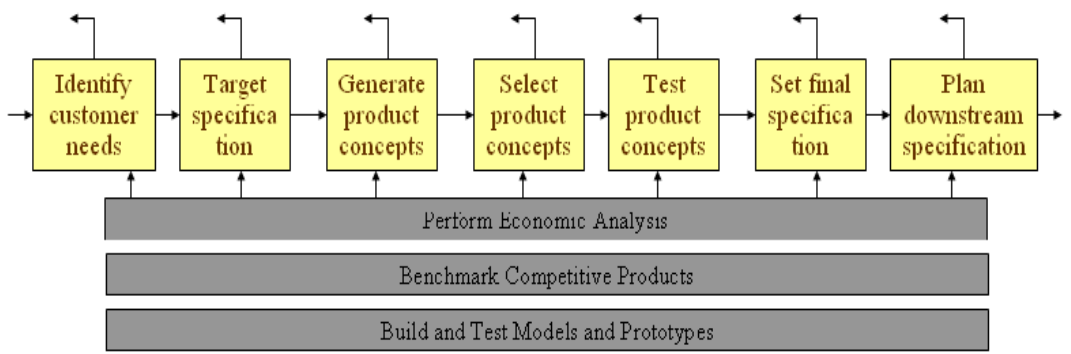

Figure 2. Concept development process. [11]

The concept development stage varies form industry to industry and product to product. Ulrich and Eppinger [11] propose a generic diagram (Figure 2) which shows the activities that must be considered for all projects. Most companies identify customer needs before the concept development process. At the target specification stage agreement on the general design functions is achieved. At the "generate product concept" stage various designs are proposed to meet the target specification. From this a few will be selected in "Select product concepts" for further investigation. At "test product concepts", the team chooses the most appropriate concept. Again, at this stage the designers do not have details of the products and just have overall shape, main features and material type.

\section{Selecting the Most Appropriate Concept using DOE}

The target specifications are set to meet the design requirements. However, they are established before the designers know what constraints the product technology will place on what can be achieved [11].

\begin{tabular}{|c|c|c|c|c|}
\hline Selection Criteria & $\begin{array}{l}\text { Plunger } \\
\text { (Reference) }\end{array}$ & Armband & Disposable Cup & Cameback \\
\hline $\begin{array}{l}\text { Ease of handling } \\
\text { Ease of use } \\
\text { Readability of setting } \\
\text { Dose metering accuracy } \\
\text { Durability } \\
\text { Ease of manufacture } \\
\text { Portability } \\
\text { COST } \\
\text { CONFIDENCE OF COST ESTIMATES }\end{array}$ & $\begin{array}{l}0 \\
0 \\
0 \\
0 \\
0 \\
0 \\
0 \\
0 \\
\mathbf{0}\end{array}$ & $\begin{array}{l}- \\
- \\
+ \\
0 \\
0 \\
- \\
0 \\
- \\
-\end{array}$ & $\begin{array}{l}+ \\
- \\
+ \\
0 \\
+ \\
0 \\
0 \\
- \\
+\end{array}$ & $\begin{array}{l}0 \\
0 \\
+ \\
+ \\
- \\
0 \\
0 \\
+ \\
-\end{array}$ \\
\hline $\begin{array}{l}\text { Surn +'s } \\
\text { Surn 0's } \\
\text { Surn -'s }\end{array}$ & $\begin{array}{l}0 \\
9 \\
0\end{array}$ & $\begin{array}{l}1 \\
0 \\
5\end{array}$ & $\begin{array}{l}4 \\
0 \\
2\end{array}$ & $\begin{array}{l}3 \\
4 \\
2\end{array}$ \\
\hline Continue? & $\begin{array}{c}0 \\
3 \\
\text { Combine }\end{array}$ & $\begin{array}{c}-4 \\
4 \\
\\
\text { No }\end{array}$ & $\begin{array}{c}2 \\
1 \\
\text { Yes }\end{array}$ & $\begin{array}{c}1 \\
2 \\
\text { Combine }\end{array}$ \\
\hline
\end{tabular}

Figure 3. Adding cost to the screening matrix. 
Hence, targets are expressed as a range of values. At the target specification the values are wide and are reduced in the final specification list. The ideal value, in the target specification, is the best result that could be hoped for and the marginal value would make a product border line for commercial viability [11]. Normally cost is often not considered in selecting the final concept. Figure 3 shows a concept screening matrix typically used by the designer to select the most appropriate concepts. One concept is used as a reference and the other compared against this and scored. This research aims to add more criteria to a typical matrix to evaluate cost, shown in the matrix in bold.

\subsection{Case Study - Fluid Dispenser for the elderly}

To illustrate this, a pilot study was undertaken, the design of a new fluid dispenser for the elderly, where the elderly needs were identified. The requirements were translated to engineering terms and a target specification created, table 1 . Seven concepts designs were created including; e.g. a plunger, disposable cup, armband, Camelback, and water cooler, all with the same target specification with the metrics in the target specification being rated in terms of functionality using QFD techniques.

Table 1 The target specification for fluid dispenser. [14]

\begin{tabular}{|c|l|c|l|}
\hline \multicolumn{2}{|c|}{ No. Metric } & Unit & \multicolumn{1}{c|}{ Value } \\
\hline $\mathbf{1}$ & Total mass when full & $\mathrm{kg}$ & $>2.1$ \\
\hline $\mathbf{2}$ & Capacity & $\mathrm{mm}$ & $>500$ \\
\hline $\mathbf{3}$ & Width & $\mathrm{mm}$ & $<150$ \\
\hline $\mathbf{4}$ & Depth & & $<2$ \\
\hline $\mathbf{5}$ & Number of actions to obtain fluid & minutes & $<2$ \\
\hline $\mathbf{6}$ & Time to clean and sterilise & seconds & $20-60$ \\
\hline $\mathbf{7}$ & Number of different drinks & & $1-10$ \\
\hline $\mathbf{8}$ & $\begin{array}{l}\text { Time to disassemble/ reassemble for } \\
\text { maintenance }\end{array}$ & $\mathrm{N}$ & $<2.32$ \\
\hline $\mathbf{9}$ & Number of parts & $\begin{array}{l}\text { Force required to operate with hands when } \\
\text { sitting }\end{array}$ & \\
\hline $\mathbf{1 0}$ & & & \\
\hline
\end{tabular}

By using DOE, designers will be able to evaluate cost and assess how changing the values of the product specification can influence cost. For example, in Table 1, if the value of capacity is $1000 \mathrm{ml}$ what will be the output in terms of cost and how accurate can the cost estimate be made? If it is changed to $1400 \mathrm{ml}$ what is the change in cost? Also they can study how changing these values influence the confidence level of cost estimates or in which value the company can have a higher cost estimate confidence level for their products in the future.

\subsection{Using DOE for the case study concepts to identify key cost factors}

DOE has been selected to evaluate the optimum cost for four shortlisted concepts. DOE can be used to determine which factors (controllable and uncontrollable) 
affect the output of a process. DOE can also be used to reduce deviation against a target. In particular it has been used to minimize the deviation of a quality characteristic from its target value in order to improve the quality of products. Considerable research has been devoted to improving the quality of products using DOE but little in optimising the quality of the cost estimate.

Table 2. Selecting factors and cost model for different concepts.

\begin{tabular}{|l|c|l|l|l|l|l|}
\hline Concept & \multicolumn{5}{|c|}{ Factors } & Cost \\
\hline Phriger & A & B & C & D & E & X \\
\hline Ammband & A & B & C & D & E & X \\
\hline Disposable & A & B & C & D & E & X \\
\hline CameIback & A & B & C & D & E & X \\
\hline
\end{tabular}

The next step in applying DOE is to select the most appropriate factor (metric) in the target specification (Table 1). Any metric in table 1 can be considered as a factor (parameters controlled by designers are called control factors) and its value can be considered as a level. For example we can name capacity factor A and 500 $\mathrm{ml}$ and $700 \mathrm{ml}$ its two different levels. After selecting the factors, the second step will be to run DOE for each concept (table 2) and the $3^{\text {rd }}$ step is to create response graphs, Figure 4. The graphs shown in Figure 4 can be used by designers to identify factors that have an impact on the cost. After selecting the most appropriate factors, for this study there were five, the next step will enable the cost to be optimised (in this case, the cheapest possible cost designers can get) for each concept and its variance to use in the screening matrix (figure 3 ) to select the most appropriate concept.

As figure 4 shows, for each different concept, designers considered five factors (A, B, C, D and E) and each of these factors has two levels. There is a cost model for each concept which can be used to see how changing these values affect cost.

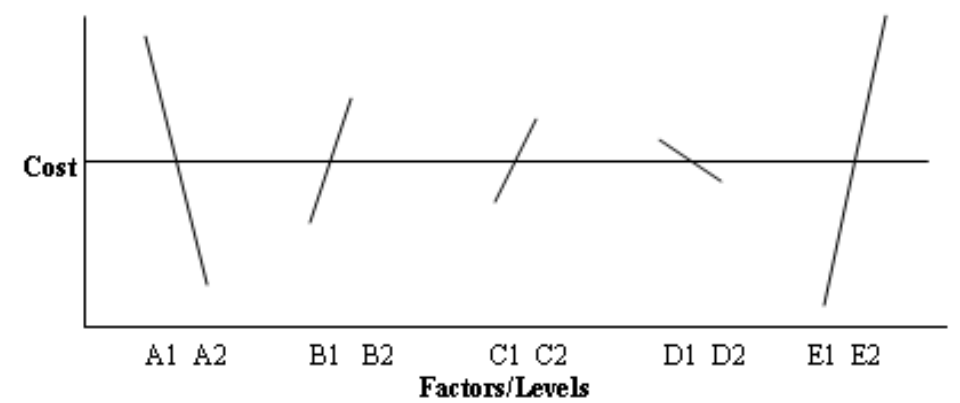

Figure 4. Example of response graph for different factors (concept 1).

This is repeated for each concept and the response graphs are created. Figure 4 shows the response graph in the Taguchi method used by designers to assess the effect of different levels for each factors. In this example the response modelled is 
cost. By using the graphs designers are able to identify which factors have more effect on cost and how changing their levels can affect cost. For example, how changing factor A from level 1 to level 2 can reduce the cost. For this example A2, $\mathrm{B} 1, \mathrm{C} 1, \mathrm{D} 2$ and $\mathrm{E} 1$, reduce the cost, however A2, E1 and B1 show the greatest impact. DOE can be run for different concept and there will be different result for each of them. Figure 5, shows the estimated cost and their confidence. This means that the minimum cost we can get for plunger is 25 with variance of 8 and the minimum cost for armband is 27 with the variance of 10 and so on.

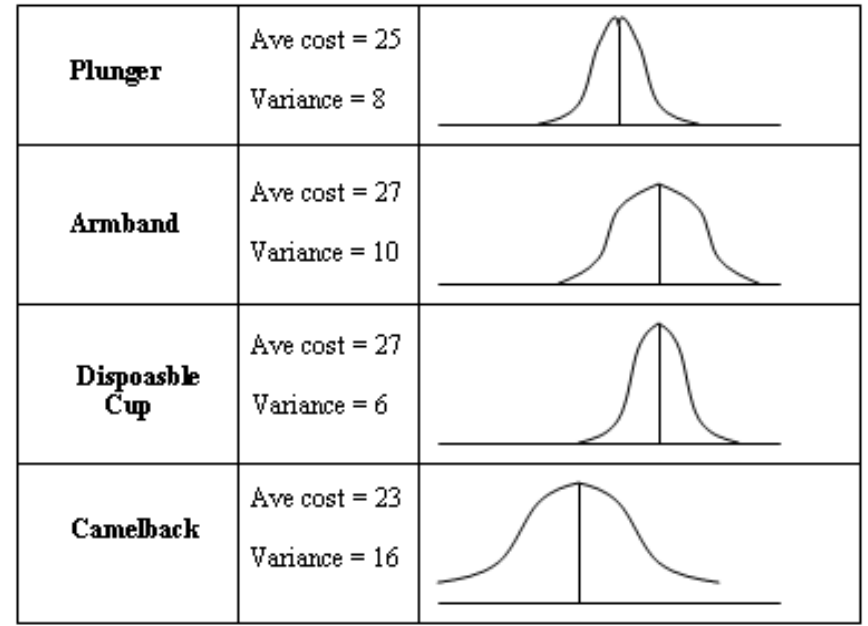

Figure 5. Example of assessing cost and variance of different concepts.

\subsection{Specification and Cost - Screening matrix}

The next stage of the approach will be to utilise the results in the concept screening matrix (Figure 3). In this case, plunger has been selected as the reference concept and other concepts will be compared to that. Any concept whose performance is better than the plunger in a specified criteria will receive a ' + ' and any concept worst than the plunger will receive a '-'. If they are the same the value is 0 . For this pilot study a benchmark cost of 27 pence with a variance of 10 has been selected for the arm band. In this case both of the values are worst than the plunger the disposable cup has a cost of $27 p$ with a variance of 6 . In this case the cost of the plunger is cheaper than the disposable cup but the variance of the disposable cup is better than the plunger. We can do the same thing for the last concept. By this method designers are able to estimate cost and confidence of their estimate and consider cost as a factor to select the most appropriate concept.

\section{Conclusion}

Nowadays a company needs to know the estimated cost precisely before it starts to detail design and manufacture a part. Cost estimation should be precise and quick 
to perform, be available as early in the design process as possible and providing valuable information to product designers. Typically $70-80 \%$ of the product cost is committed by the end of the conceptual design stage. . The main aim of this research is to use the Taguchi Method of Design of Experiments to use the sparse concept information more effectively to estimate the cost of a product.

The use of DOE has been demonstrated via a case study to assess the product specification and find the optimum solution with a high level of confidence in the cost estimate. By using this technique designers are able to evaluate cost and assess how changing the values of the product specification can influence cost. This technique can then be used to identify which of the values has the greater contribution to the product cost, and also then enable negotiations over the specification between need and preferred requirements.

Using the fluid dispenser for the elderly as an exemplar the way of selecting factors and running DOE for each concept has been presented. Also how Taguchi method can be used to estimate optimum cost with higher confidence level has been discussed. From here the findings are then presented in a typical design screening matrix to assist designers to consider cost as a critical factor to select the most appropriate concept.

\section{References}

[1] Asideu, Y. and Eu, P. (1998). Product life cycle cost analysis: state of the art review. International journal of production research, 36(4), 883-908.

[2] Corbett, J. (1986). Design for economic manufacture. CIRP., 35(1), 93-97.

[3] Mileham, A. R., Currie, C. G., et al. (1992). Conceptual cost information as an aid to the designer. International operation: crossing borders in manufacturing and service, Elsevier Science Publisher. 199-124.

[4] Mileham, A. R., Currie, C. G., et al. (1993). A parametric approach to cost estimation at the conceptual stage of design. Journal of engineering design. 4(2), 117-125.

[5] Farineau, T., et al. (2001). Use of parametric models in an economic evaluation step during the design phase. International journal of advanced manufacturing technology, 17(2), 79-86.

[6] Roy, R. (2003). Cost engineering: why, what and how. Cranfield, Cranfield University.

[7] Niazi, A., Dai, J. S. (2006). Product cost estimation: technique classification and methodology. Journal of manufacturing science and engineering. 128: 13.

[8] Cmarago, M., et al. (2003). Application of parametric cost estimation in the textile supply chain. Journal of textile and apparel, technology and management. 3(1), 1-12.

[9] Ayed, A. S. (1997). Parametric cost estimation of highway projects using neural networks. Engineering Newfoundland, Canada, Master of science, 87

[10] Raymer, D. P. (1999). Aircraft design: a conceptual approach. American institute of aeronautics and astronautics, Inc, London, UK.

[11] Ulrich, K. T., Eppinger, S. D. (2003). Product design and development. McGraw-Hill higher education; 3 edition. New York, NY, USA.

[12] Ullman, D. G. (2003). The mechanical design process, McGraw-Hill. Boston/London.

[13] Pahl, G., Beitz,W., et al. (2007). Engineering Design. Spring-verlag London limited, $3^{\text {rd }}$ edition, London, UK.

[14] Bennett, Chris. 'Design of a fluid dispenser for the elderly', specialist design project, Dept. mechanical Eng. University of Bath, Claverton Down, BA2 7AY 